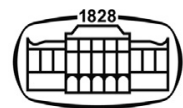

AKADÉMIAI KIADÓ

\title{
A retrospective study on the presence of selected infectious agents in lung samples of cats with pneumonia
}

\section{Acta Veterinaria Hungarica}

$68(2020) 3,275-284$

DOI:

10.1556/004.2020.00037

(c) 2020 Akadémiai Kiadó, Budapest

ORIGINAL RESEARCH PAPER

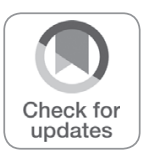

*Corresponding author. Tel.: +43 (1) 250772400

E-mail: herbert.weissenboeck@ vetmeduni.ac.at

\author{
EVA SCHMAL-FILIUS, NORA NEDOROST, \\ CHRISTIANE WEISSENBACHER-LANG and \\ HERBERT WEISSENBÖCK* ${ }^{*}$
}

Department of Pathobiology, Institute of Pathology, University of Veterinary Medicine Vienna, Veterinärplatz 1, A-1210 Vienna, Austria

Received: January 31, 2020 • Accepted: May 8, 2020

Published online: November 20, 2020

\section{ABSTRACT}

The causative role of some infectious agents found in cases of feline pneumonia is under debate, because they are also part of the physiological microbiota of the respiratory tract of healthy animals. In this retrospective study, archived formalin-fixed and paraffin-wax-embedded lung samples of 69 severe and lethal cases of pneumonia in cats were examined by immunohistochemistry (IHC) for the detection of nine selected infectious agents: Pasteurella multocida, Bordetella bronchiseptica, Mycoplasma felis, M. gateae, Chlamydia felis, feline herpesvirus type 1, feline coronavirus, canine distemper virus, and Toxoplasma gondii. The intention was to elucidate their immediate involvement in pneumonia formation. Due to the cross-reactivity of the applied antibodies, a species-specific polymerase chain reaction (PCR) for both targeted Mycoplasma species was applied additionally. In the 42 cases (60.9\%) positive for at least one pathogen, several agents were present in a high proportion of the samples (P. multocida $-34.8 \%$, B. bronchiseptica $-29.0 \%$ ), while others were present in a moderate (feline herpesvirus type $1-18.8 \%$, M. gateae $-13.0 \%$, M. felis $-10.1 \%$ ) or low percentage (T. gondii $-1.4 \%$ ). All samples were negative for $C$. felis, feline coronavirus and canine distemper virus. Mixed infections of up to four pathogens were more frequent than single infections. Mycoplasma preferably colonised lung tissue damaged by other pathogens because they never occurred as single infections. Pasteurella multocida, B. bronchiseptica, M. felis, feline herpesvirus type 1 and T. gondii showed abundant replication within lung lesions, thus suggesting a prominent role in pneumonia formation.

\section{KEYWORDS}

cat, pneumonia, retrospective study, feline herpesvirus type 1, Bordetella bronchiseptica, Pasteurella multocida, Mycoplasma felis, Mycoplasma gateae, Toxoplasma gondii

\section{INTRODUCTION}

Infectious respiratory disease in cats is a common problem, and especially young animals may be affected with severe, sometimes lethal pneumonia. Pneumonia in cats can be caused by a large variety of pathogens including viruses, bacteria, parasites and fungi. By clinical sampling (such as swabs or bronchoalveolar lavage) most of these pathogens may be discovered; however, it frequently remains unclear whether they are opportunistic commensals or causative agents of the observed pneumonias. In this retrospective study, archived formalin-fixed and paraffin-wax-embedded lung samples of severe and lethal cases of pneumonia in cats were examined by immunohistochemistry (IHC) for the detection of several infectious agents.

The study cannot claim to provide an exhaustive overview of all infectious agents with potential respiratory tract pathogenicity. We focused on some well-known respiratory pathogens [such as feline herpesvirus type 1 (FHV-1) or Bordetella bronchiseptica], less 
investigated agents in context with feline pneumonias [such as canine distemper virus (CDV), feline coronavirus (FCoV), Chlamydia felis, Toxoplasma gondii], and pathogens that are frequently found in the feline respiratory tract but their primary causative role in pneumonias is under debate (such as Pasteurella multocida, Mycoplasma felis and M. gateae).

FHV-1 is an important pathogen in feline upper respiratory tract infections (Bannasch and Foley, 2005). It causes necrotic lesions of the nasal epithelium with secondary spread to the conjunctival sac, oropharynx and trachea. However, it is a rare cause of pneumonia (Foster and Martin, 2011), which is predominantly found in kittens (Gaskell and Dawson, 1998; Chvala-Mannsberger et al., 2009). Persistently infected carrier cats appearing to be healthy or cats with clinically active forms of the infection are the principal source of virus. Stress or corticosteroid administration may lead to genome activation and virus shedding (Gaskell and Povey, 1973, 1977; Gaskell et al., 2007).

FCoV is divided into two biotypes, known as feline enteric coronavirus (FECV) and feline infectious peritonitis virus (FIPV) (Pedersen et al., 1981; Pedersen, 1987). In the majority of naturally infected animals, FCoV infection remains subclinical, with generalised B and T cell hyperplasia, but no other pathological findings. A minority of cats, however, develops feline infectious peritonitis (FIP), a fatal systemic granulomatous disease, characterised by fibrinousgranulomatous serositis with protein-rich effusions into body cavities, granulomatous-necrotising phlebitis and periphlebitis and granulomatous inflammatory lesions in several organs, including the lungs (Kipar et al., 2006).

$\mathrm{CDV}$ is a common pathogen in large felids. Currently, there is no evidence that the virus is pathogenic for domestic cats (Bart et al., 2000), but studies investigating the involvement in feline diseases are scarce. Experimental infections did not result in clinical signs, but induced seroconversion (Appel et al., 1974). Therefore, we intended to screen for this pathogen as a potential causative agent of pneumonia as well.

Bordetella bronchiseptica is considered a primary respiratory pathogen in cats and has been associated with tracheobronchitis, conjunctivitis and rhinitis (upper respiratory disease), mandibular lymphadenopathy, and pneumonia (Willoughby et al., 1991; Foley et al., 2002). The clinical importance of isolation or positive testing is not well established, because $B$. bronchiseptica has been frequently found in clinically healthy cats (Foley et al., 2002).

Pasteurella multocida is part of the physiological microbiota of the naso- and oropharynx in cats, but it can also be found in cases of fibrinopurulent pneumonia (Ames et al., 1985).

Chlamydia felis appears to be primarily a pathogen of the upper airways; it infects the conjunctiva and nasal mucosa rather than the lungs (Hoover et al., 1978; Bart et al., 2000). A few Chlamydia strains have been detected in pneumonic lungs (Baker, 1942, 1944), but there are no convincing reports that this pathogen causes pneumonia by natural infection in cats. So far only experimental intranasal infection has been reported to produce small foci of bronchointerstitial pneumonia (Baker, 1944; Hoover et al., 1978).
Mycoplasma spp. and their role in upper and lower airway diseases is still a matter of debate. Some investigators believe Mycoplasma only colonises inflamed or infected lower airways, while others believe that Mycoplasma species are capable of being a primary cause of pneumonia (Chandler and Lappin, 2002; Trow et al., 2008). Mycoplasma spp. have been shown to be inhabitants of mucosal surfaces of the respiratory tract, urogenital tract, eyes, gastrointestinal tract and the joints of cats (Campbell et al., 1973; Haesebrouck et al., 1991; Foster et al., 2004b; Liehmann et al., 2006; Zeugswetter et al., 2006). Some of these studies also provide evidence that Mycoplasma causes inflammation in these areas. Concerning the respiratory tract, it is accepted that these agents belong to the normal microbiota of the upper airways, such as the larynx, pharynx, and nasal cavity (Rosendal, 1982; Chandler and Lappin, 2002), while they are not commonly found in the healthy lower respiratory tract (Foster et al., 2006; Trow et al., 2008). Mycoplasma felis has been associated with pneumonia in cats; however, it is not entirely clear whether it acts as a primary pathogen, opportunistic invader or merely colonisers of altered tissue sites (Foster et al., 2006). In this morphologically dominated study, emphasis will be placed upon the question whether M. felis and M. gateae, two Mycoplasma species frequently encountered in cats, co-localise with specific inflammatory lesions.

In cats, a frequent manifestation of clinical toxoplasmosis has been shown to be respiratory tract disease including pneumonia (Dubey and Carpenter, 1993). Thus, also screening for this parasite is part of the present study.

The presence of these nine pathogens was assessed by the use of IHC. The major aim of the study was to evaluate the prevalence of the above-mentioned infectious agents and to explore their causative role by means of determining their abundance and co-localisation with inflammatory lesions.

\section{MATERIALS AND METHODS}

\section{Tissue samples and histopathology}

Formalin-fixed, paraffin wax-embedded lung tissue samples of 69 cats from the archive of the Institute of Pathology (University of Veterinary Medicine Vienna) were used. These samples originated from cats that had been necropsied between 1999 and 2006 and in which pneumonia had been diagnosed histologically. Proven cases of aspiration pneumonia, which is often seen in young animals, and obvious cases of thoracic manifestations of FIP were excluded from this study.

Data concerning signalment (breed, sex, age), housing conditions, clinical signs, results of postmortem examination and recorded laboratory findings from initial bacteriological and parasitological examinations were collected. The cats were assigned to the following age groups: five days to twelve weeks (19 cases), 13 weeks to six months (nine cases), seven months to twelve months (nine cases), one year to six years (13 cases), seven years to 15 years (14 cases). In five cases the age was not recorded. 
The investigated cats belonged to the following breeds: European Shorthair (51), Siamese (3), British Shorthair (3), Persian (3), Maine Coon (3), Ragdoll (1), Ragamuffin (1), European Longhair (1) and Norwegian Forest cat (1). In two cases, the breed was not recorded.

All lung samples were stained with haematoxylin and eosin (HE) according to standard techniques and the lung lesions were classified regarding type, severity and distribution.

\section{Immunohistochemistry (IHC)}

For IHC, lung tissue sections $(3-4 \mu \mathrm{m})$ were mounted on SuperFrostPlus $^{\odot}$ slides (Menzel-Gläser, Braunschweig, Germany). The avidin-biotin-complex peroxidase method was used for the detection of infectious agents. Following dewaxing and rehydration, antigen retrieval was achieved by heating the slides in citrate buffer $(\mathrm{pH}$ 6.0) in a microwave oven, except for FHV-1, where the slides were placed in $0.1 \%$ pronase (Protease type XIV, Sigma Aldrich, Steinheim, Germany) for $5 \mathrm{~min}$ at $37{ }^{\circ} \mathrm{C}$. Endogenous peroxidase activity was blocked with $0.3 \%$ $\mathrm{H}_{2} \mathrm{O}_{2}$ in methanol for $30 \mathrm{~min}$. The sections were then incubated with a 1:10 dilution of normal goat serum (Vector Laboratories, Burlingame, CA, USA) for $60 \mathrm{~min}$, followed by overnight incubation with the diluted primary antibody (Table 1). After washing in phosphate-buffered saline, the tissues were incubated with a 1:400 dilution of biotinylated anti-mouse or anti-rabbit IgG, depending on the origin of the primary antibody, for $30 \mathrm{~min}$, followed by the Vectastain ABC kit (Vector Laboratories) for 60 min. The reaction was visualised with DAB Substrate Kit for Peroxidase (Vector Laboratories). After counterstaining with haemalum and dehydration, the slides were placed under coverslips with Neomount (VWR, Vienna, Austria). Each run was accompanied by respective positive controls.

\section{Polymerase chain reaction (PCR)}

In the case of Mycoplasma, previous investigations (Wöhrer et al., 2016) suggested that cross-reactivity between $M$. felis and M. gateae antigens might lead to inaccurate IHC results. Thus species-specific primers, targeting a portion of the $16 \mathrm{~S}$ ribosomal RNA gene, used in polymerase chain reaction (PCR) were designed with the aid of Primer designer 4.0 of the Sci Ed Central Software package (Scientific Educational Software, Cary, NC, USA). After alignment of available sequences from GenBank, suitable specific primers were selected and tested for specificity on pure cultures from $M$. felis and M. gateae (kindly provided by J. Spergser, Institute of Microbiology, University of Veterinary Medicine, Vienna), respectively. The primers $M$. felis fw: $5^{\prime}$-CGG AGT ACA AKT TAC AAT TC- $3^{\prime}$ and $M$. felis rv: $5^{\prime}$-ACT CGG TAT CAC AAA ACA AA- $3^{\prime}$ were used for amplification of $M$. felis, resulting in a 216 -bp amplification product. The primers $M$. gateae fw: $5^{\prime}$-GAC CGC CTA AGG TAG GAC TG- $3^{\prime}$ and $M$. gateae rv: $5^{\prime}$-CTC CGT TGA AAG GAG GTG AT- $3^{\prime}$ were used for amplification of M. gateae, resulting in a 91-bp amplification product. All samples immunohistochemically positive for $M$. felis, M. gateae or both were subjected to PCR. For PCR amplification, paraffin wax sections $(10 \mu \mathrm{m})$ were dewaxed in xylene and afterwards washed in ethanol and dried. DNA was extracted using Nexttec Clean Columns (Nexttec, Leverkusen, Germany) according to the manufacturer's instructions. For amplification, the $25-\mu \mathrm{L}$ reaction mixture was composed of $12.5 \mu \mathrm{L}$ KAPA2G Fast HotStart ReadyMix with Dye (2x) (Sigma Aldrich, Vienna, Austria), $1 \mu \mathrm{L}$ of each forward and reverse primer $(10 \mathrm{pM}), 1 \mu \mathrm{L}$ of $\mathrm{MgCl}, 7.5 \mu \mathrm{L}$ of distilled water and $2 \mu \mathrm{L}$ of template DNA. The cycling profile consisted of an initial denaturation at $95^{\circ} \mathrm{C}$ for $3 \mathrm{~min}$, followed by 40 cycles of heat denaturation at $95^{\circ} \mathrm{C}$ for $15 \mathrm{~s}$, primer annealing at $50{ }^{\circ} \mathrm{C}$ (M. felis) and $60^{\circ} \mathrm{C}$ (M. gateae) for $15 \mathrm{~s}$ and DNA extension at $72{ }^{\circ} \mathrm{C}$ for $25 \mathrm{~s}$, and ended with a final extension at $72{ }^{\circ} \mathrm{C}$ for $1 \mathrm{~min}$.

In selected cases $(13,28,35)$ the identity of the amplification products was analysed by sequencing (Microsynth, Balgach, Switzerland).

\section{RESULTS}

\section{Tissue samples and histopathology}

In 17 (24.6\%) of the investigated cases upper airway diseases with signs such as rhinitis, laryngitis, conjunctivitis and tracheitis were communicated in the clinical anamnesis.

Histological lung lesions allowed assignment of the cases to the following groups: lesions typical for suppurative bronchopneumonia, including purulent exudate in the

Table 1. Antibodies used for immunohistochemistry, their source and working dilution

\begin{tabular}{lccc}
\hline Pathogen & Antibody type, host species & Source & Dilution \\
\hline Feline herpesvirus type 1 & monoclonal (4A1R), mouse & L. Haas, Hannover, Germany & $1: 500$ \\
Feline coronavirus & monoclonal (1CD7), mouse & Ingenasa, Madrid, Spain & $1: 5,000$ \\
Canine distemper virus & monoclonal, mouse & C. Örvell, Stockholm, Sweden & $1: 10,000$ \\
Pasteurella multocida & polyclonal, rabbit & Institute Microb., Vetmeduni & $1: 30,000$ \\
Bordetella bronchiseptica & polyclonal, rabbit & K. Register, Ames, IA, USA & $1: 3,000$ \\
Mycoplasma felis & polyclonal, rabbit & Institute Microb., Vetmeduni & $1: 10,000$ \\
Mycoplasma gateae & polyclonal, rabbit & Institute Microb., Vetmeduni & $1: 20,000$ \\
Chlamydia sp. & monoclonal, mouse & Progen, Heidelberg, Germany & $1: 100$ \\
Toxoplasma gondii & polyclonal, rabbit & NeoMarkers, Fremont, CA, USA & $1: 1,000$ \\
\hline
\end{tabular}


alveoli (Fig. 1A), bronchioles and bronchi, in many cases associated with multifocal to coalescing necrosis of pulmonary tissue (Fig. 1B) were present in 32 cats (46.4\%). Twenty cases $(29.0 \%)$ were diagnosed as fibrinous or fibrinonecrotic pneumonia (Fig. 1C). In 14 cases (20.3\%), interstitial pneumonia (Fig. 1D), among them twelve (17.4\%) with an additional purulent or fibrotic component, was found. In three cats $(5.8 \%)$ bronchointerstitial pneumonia was diagnosed histologically, all of them accompanied by either fibrinonecrotic pneumonia or suppurative bronchopneumonia. Seven $(10.2 \%)$ of the cats with pneumonia (four cases of suppurative pneumonia, three cases of fibrinous pneumonia) additionally showed signs of septicaemia, including bacterial emboli in blood vessels and multifocal acute vascular and perivascular inflammatory infiltrates in internal organs.

\section{Immunohistochemistry and PCR}

Forty-two cases (60.9\%) were positive for at least one of the pathogens investigated in this study. In 25 (59.5\%) out of these 42 positive cases more than one pathogen could be detected. These cases are summarised in Table 2.

In 24 cases $(34.8 \%)$ antigens of $P$. multocida were detected immunohistochemically (Fig. 2A). The labelling could be attributed to intraalveolar bacterial colonies and was also found intracellularly within macrophages or neutrophils. In five of these cats also septicaemia was noted. The age distribution was rather even, with eleven cases below one year of age and eleven cases older than one year. In two cases the age was not recorded.
Twenty cases $(29.0 \%)$ were positive for antigens of $B$. bronchiseptica (Fig. 2B). Positive signals were predominantly present in intraalveolar bacterial colonies and also within (fibrino)-necrotic tissue lesions. Intracellular presence of these bacterial antigens was only exceptionally seen. This infection was less common in the younger age group (eight cases up to the age of one year, eleven cases older than one year; one case with no registered age).

In 20 cases $(29.0 \%)$ there was a positive reaction with the M. felis antibody in the investigated lungs (Fig. 2C). The IHC signal was predominantly found in alveolar spaces, attached to the bronchial or bronchiolar epithelial cells, or within fibrinonecrotic lesions. While the mycoplasmal antigen was predominantly seen within the cytoplasm of macrophages and neutrophils in alveolar locations, it appeared mostly extracellular in the latter two sites. One cat had accompanying septicaemia with mycoplasmal antigens present within blood vessels.

Seventeen cases $(24.6 \%)$ were reactive with the $M$. gateae antibody. In these positive cases, one cat had an additional septicaemia. The distribution of the antigens was comparable to the distribution in M. felis cases. Of the 20 cases with a positive reaction with the $M$. felis antibody, 16 were also reactive with the $M$. gateae antibody and 16 of the $17 M$. gateae-positive cases were reactive with the $M$. felis antibody.

In order to test whether these results reflected true double infections or resulted from cross-reactivity of the antibodies, M. felis- and M. gateae-specific PCR assays were performed. The assays proved to be species specific, as shown by selective amplification of pure culture samples. All
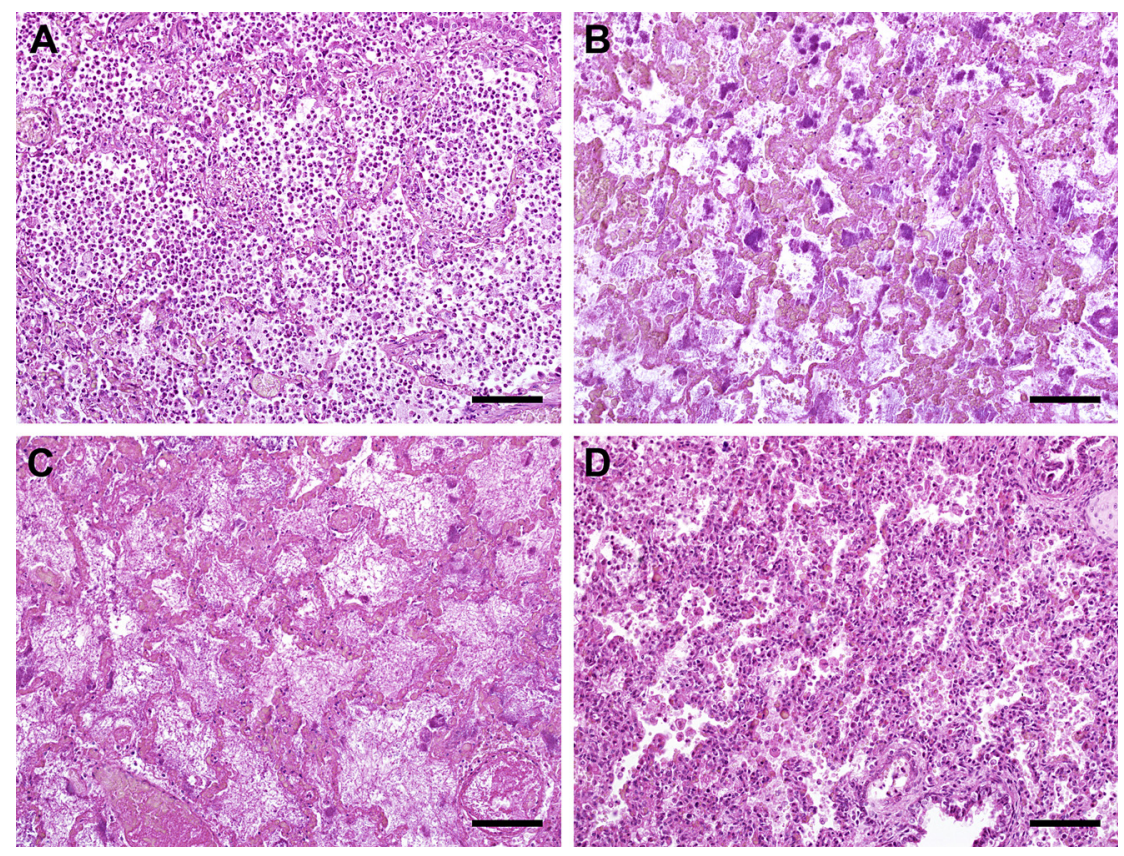

Fig. 1. Frequent histological features of the observed pneumonias in cats. (A) Suppurative pneumonia is characterised by large numbers of neutrophils within alveolar spaces. (B) In many cases widespread areas of bacterially colonised coagulation necroses are present. (C) In fibrinous or fibrinonecrotic pneumonia the alveolar spaces are filled with fibrin. (D) Interstitial pneumonia shows thickening of alveolar walls by increased cellularity accompanied by intraalveolar accumulations of alveolar macrophages. Bars $=80 \mu \mathrm{m}$ 
Table 2. Detailed results of immunohistochemical and PCR pathogen screening in all positive animals, including data on pneumonia type, age and sex

\begin{tabular}{|c|c|c|c|c|c|c|c|c|c|}
\hline No. & P. multocida & B. bronchiseptica & M. felis & M. gateae & FHV -1 & T. gondii & Type of pneumonia & Sex & Age \\
\hline 1 & & $\mathrm{x}$ & $\mathrm{x}$ & & $\mathrm{x}$ & & sup. $\mathrm{P}$. & $\mathrm{f}$ & $3 \mathrm{~m}$ \\
\hline 2 & $\mathrm{x}$ & & & & & & fibr. $\mathrm{P}$ & $\mathrm{f}$ & $10 \mathrm{w}$ \\
\hline 3 & & $\mathrm{x}$ & $\mathrm{x}$ PCR+ & $\mathrm{x}$ & & & sup. P. & $\mathrm{f}$ & $5 \mathrm{y}$ \\
\hline 4 & $\mathrm{x}$ & $\mathrm{x}$ & $\mathrm{x}$ & $\mathrm{x}$ PCR+ & & & interst. P. & $\mathrm{m}$ & unknown \\
\hline 5 & $\mathrm{x}$ & & & & & & sup. P. & $\mathrm{m}$ & $5 \mathrm{y}$ \\
\hline 6 & $\mathrm{x}$ & $\mathrm{x}$ & & $\mathrm{x}$ & & & fibr. P. & $\mathrm{m}$ & $10 \mathrm{y}$ \\
\hline 7 & $\mathrm{x}$ & $\mathrm{x}$ & x PCR+ & $\mathrm{x}$ & & & fibr. P. & $\mathrm{m}$ & adult \\
\hline 8 & $\mathrm{x}$ & & $\mathrm{x}$ PCR+ & $\mathrm{x}$ PCR+ & & & fibr. P. & $\mathrm{m}$ & $3 \mathrm{~m}$ \\
\hline 9 & $\mathrm{x}$ & & & & & & sup. P. & $\mathrm{f}$ & $12 \mathrm{y}$ \\
\hline 10 & & & & & $\mathrm{x}$ & & interst. P. & $\mathrm{m}$ & $3 \mathrm{w}$ \\
\hline 11 & & $\mathrm{x}$ & $\mathrm{x}$ & $\mathrm{x}$ & & & fibr. P. & $\mathrm{m}$ & $14 \mathrm{y}$ \\
\hline 12 & $\mathrm{x}$ & $\mathrm{x}$ & $\mathrm{x}$ PCR + & $\mathrm{x}$ & & & interst.P & $\mathrm{m}$ & adult \\
\hline 13 & & $\mathrm{x}$ & $\mathrm{x}$ PCR+ & $\mathrm{x}$ & & & sup. P. & $\mathrm{f}$ & $6 \mathrm{~m}$ \\
\hline 14 & & $\mathrm{x}$ & & & & & fibr. P. & $\mathrm{m}$ & $7 \mathrm{~m}$ \\
\hline 15 & & $\mathrm{x}$ & $\mathrm{x}$ & $\mathrm{x}$ & & & sup. P. & $\mathrm{f}$ & $14 \mathrm{y}$ \\
\hline 16 & & & & & $\mathrm{x}$ & & interst. P. & $\mathrm{m}$ & $10 \mathrm{w}$ \\
\hline 17 & $\mathrm{x}$ & $\mathrm{x}$ & $\mathrm{x}$ & $\mathrm{x}$ & & & sup. P. & $\mathrm{m}$ & $5 \mathrm{~m}$ \\
\hline 18 & $\mathrm{x}$ & & $\mathrm{x}$ & $\mathrm{x}$ PCR + & & & sup. P. & $\mathrm{m}$ & $3 y$ \\
\hline 19 & & & & & $\mathrm{x}$ & & interst. P. & $\mathrm{f}$ & unknown \\
\hline 20 & & & & & $\mathrm{x}$ & & fibr. P. & $\mathrm{m}$ & $8 \mathrm{~m}$ \\
\hline 21 & $\mathrm{x}$ & & & & & & fibr. P. & $\mathrm{f}$ & $6 \mathrm{w}$ \\
\hline 22 & $\mathrm{x}$ & & & & & & sup. P. & $\mathrm{m}$ & $5 \mathrm{~d}$ \\
\hline 23 & $\mathrm{x}$ & $\mathrm{x}$ & $\mathrm{x}$ & $\mathrm{x}$ PCR+ & & & sup. P. & $\mathrm{f}$ & juvenile \\
\hline 24 & $\mathrm{x}$ & & $\mathrm{x}$ PCR+ & $\mathrm{x}$ PCR+ & & & sup. P. & $\mathrm{m}$ & $1,5 \mathrm{y}$ \\
\hline 25 & $\mathrm{x}$ & $\mathrm{x}$ & & & & & sup. P. & $\mathrm{f}$ & $10 \mathrm{w}$ \\
\hline 26 & $\mathrm{x}$ & & $\mathrm{x}$ PCR+ & & $\mathrm{x}$ & & interst. P. & $\mathrm{m}$ & $4 \mathrm{w}$ \\
\hline 27 & $\mathrm{x}$ & $\mathrm{x}$ & $\mathrm{x}$ & $\mathrm{x}$ PCR+ & & & fibr. P. & $\mathrm{f}$ & $6 y$ \\
\hline 28 & $\mathrm{x}$ & & $\mathrm{x}$ & $\mathrm{x}$ PCR+ & & & fibr. P. & $\mathrm{m}$ & $6 \mathrm{~m}$ \\
\hline 29 & & & & & $\mathrm{x}$ & & interst. P. & $\mathrm{f}$ & $9.5 \mathrm{y}$ \\
\hline 30 & $\mathrm{x}$ & & & & $\mathrm{x}$ & & sup. P. & $\mathrm{f}$ & $10 \mathrm{y}$ \\
\hline 31 & & & & & $\mathrm{x}$ & $\mathrm{x}$ & bronchoint. P. & $\mathrm{m}$ & $8 \mathrm{y}$ \\
\hline 32 & & $\mathrm{x}$ & & & & & fibr. P. & $\mathrm{f}$ & $4 \mathrm{y}$ \\
\hline 33 & $\mathrm{x}$ & $\mathrm{x}$ & & & & & fibr. P. & $\mathrm{f}$ & $6 y$ \\
\hline 34 & $\mathrm{x}$ & $\mathrm{x}$ & $\mathrm{x}$ PCR + & $\mathrm{x}$ PCR+ & $\mathrm{x}$ & & sup. $\mathrm{P}$. & $\mathrm{f}$ & adult \\
\hline 35 & & & $\mathrm{x}$ PCR + & & $\mathrm{x}$ & & sup. P. & $\mathrm{f}$ & $10 \mathrm{y}$ \\
\hline 36 & $\mathrm{x}$ & $\mathrm{x}$ & $\mathrm{x}$ & $\mathrm{x} \mathrm{PCR}+$ & & & sup. P. & $\mathrm{f}$ & $6 \mathrm{~m}$ \\
\hline 37 & & & & & $\mathrm{x}$ & & sup. P. & $\mathrm{f}$ & $1.5 \mathrm{y}$ \\
\hline 38 & $\mathrm{x}$ & & & & & & sup. P. & $\mathrm{f}$ & unknown \\
\hline 39 & $\mathrm{x}$ & & $\mathrm{x}$ & & & & fibr. P. & $\mathrm{f}$ & $6 \mathrm{~d}$ \\
\hline 40 & & $\mathrm{x}$ & & & & & fibr. P. & $\mathrm{m}$ & $3 \mathrm{~m}$ \\
\hline 41 & & $\mathrm{x}$ & & & & & sup. P. & $\mathrm{m}$ & $3 y$ \\
\hline 42 & & & & & $\mathrm{x}$ & & interst. P. & $\mathrm{m}$ & $7 \mathrm{~m}$ \\
\hline Total & 24 & 20 & $20(8)$ & $18(9)$ & 13 & 1 & & & \\
\hline
\end{tabular}

sup. P. = suppurative pneumonia; fibr. P. = fibrinous pneumonia; interst. P. = interstitial pneumonia; bronchoint. P. = bronchointerstitial pneumonia. $\mathrm{f}=$ female; $\mathrm{m}($ column: Sex $)=$ male; d: days; $\mathrm{m}($ column: Age $)=$ months; $\mathrm{y}=$ years; $\mathrm{PCR}+=$ positive PCR result.

cases with a positive IHC reaction for M. felis, M. gateae or both were subjected to PCR. Mycoplasma felis PCR yielded positive results in nine cases, and M. gateae PCR was positive in nine cases as well. In only three cases, both PCRs were positive in the same animal.

In 20 cases positive by $M$. felis IHC, $M$. felis infection was confirmed in only nine cases, while an obvious cross-reaction with M. gateae was suggested by M. gateae-positive PCR results in another six cases. In five IHC-positive cases, the PCR had negative results.
Of the 17 IHC-positive $M$. gateae cases nine were confirmed by PCR, while in four an obvious cross-reaction with $M$. felis was seen. There were four cases with an entirely negative PCR result. In PCR-positive M. gateae cases that also showed immunostaining with the M. gateae antibody there were scarce and very localised reaction products (Fig. 2D), suggesting a low proliferation rate of this Mycoplasma species in diseased lungs. Sequencing of amplification products of three cases ( 2 M. felis, 1 M. gateae) proved the specificity of the PCR assays. 

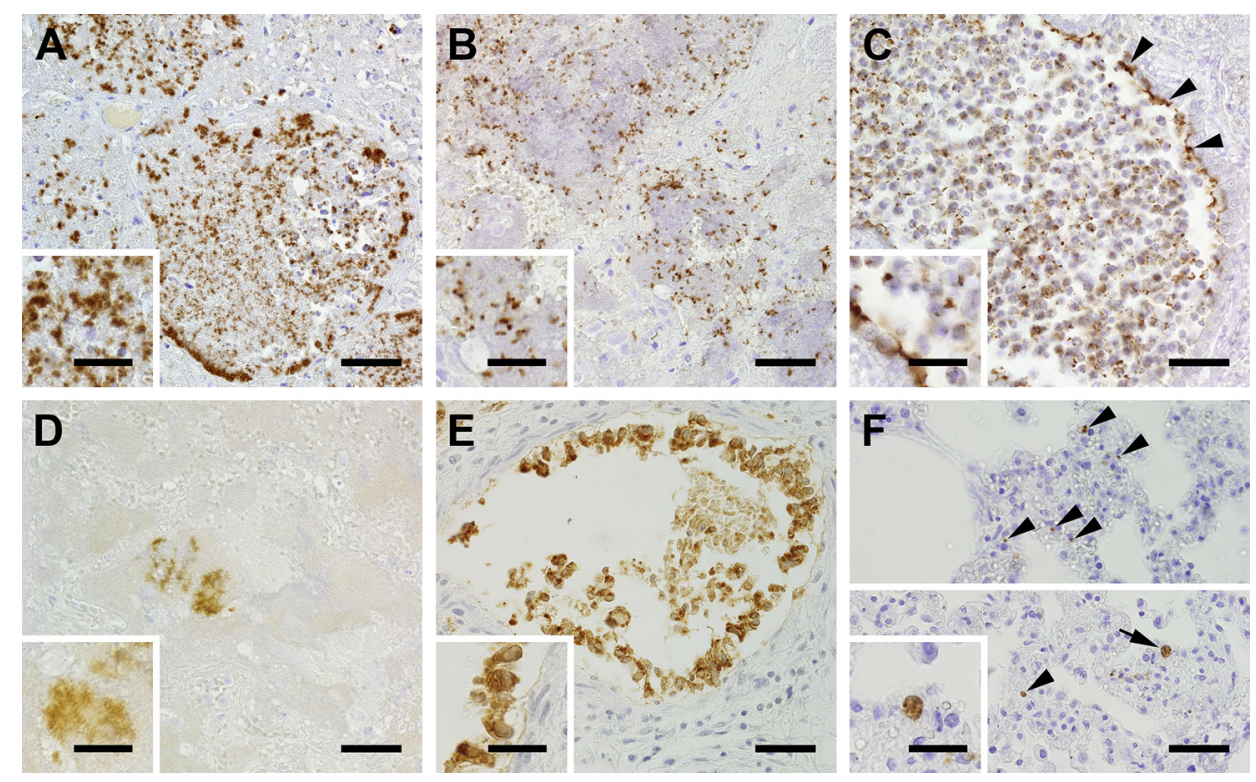

Fig. 2. Immunohistochemical demonstration of the antigens of Pasteurella multocida (A), Bordetella bronchiseptica (B), Mycoplasma felis (C), Mycoplasma gateae (D), feline herpesvirus type 1 (E), and Toxoplasma gondii (F) in the lung tissue of cats. Antigens of Pasteurella, Bordetella and M. gateae are predominantly abundant in necrotic tissue. Mycoplasma felis is attached to the bronchiolar epithelium (arrows) and present within the cytoplasm of neutrophils. Tachyzoites (arrowheads) and a small cyst (arrow) of T. gondii are found within alveolar epithelial cells.

Bars $(\mathrm{A}-\mathrm{F})=40 \mu \mathrm{m}$. Insets (bars $=20 \mu \mathrm{m}$ ) show higher magnifications of the stained pathogens and infected cells, respectively

The PCR-confirmed M. felis and M. gateae cases were found in all age categories with no obvious differences between the two Mycoplasma species.

FHV-1 was detected in 13 cases (18.8\%). Viral antigen was present in (partially necrotic) bronchial and bronchiolar epithelial cells (Fig. 2E), pneumocytes lining the alveolar spaces and alveolar macrophages. FHV-1 IHC was positive in four cases under twelve weeks, in just one case between three months and six months, in two cases between six months and twelve months, and in six cases older than one year.

One case was positive for T. gondii. This FHV-1-positive cat showed an acute toxoplasmosis and numerous tachyzoites were present predominantly within the alveolar epithelial cells and alveolar macrophages (Fig. 2F). The animal was ten weeks old.

In none of the investigated lung samples could antigens of CDV, Chlamydia spp. and FCoV be detected.

\section{Pathogens and associated lung lesions, co-infections}

Cases positive for P. multocida exhibited predominantly suppurative pneumonia (12) and fibrinous pneumonia (9), and only infrequently interstitial pneumonia (3).
Infections with $B$. bronchiseptica showed predominantly suppurative pneumonia (10), followed by fibrinous pneumonia (8) and interstitial pneumonia (2).

PCR-confirmed $M$. felis infections were most frequently associated with suppurative pneumonia (5), followed by fibrinous pneumonia (2) and interstitial pneumonia (2).

Also PCR-confirmed M. gateae-positive cases had similar frequencies of pneumonia types: suppurative pneumonia (4), fibrinous pneumonia (3), and interstitial pneumonia (2).

FHV-1 cases predominantly exhibited interstitial pneumonia (6) followed by suppurative pneumonia (5), bronchointerstitial pneumonia (1) and fibrinous pneumonia (1).

Co-infections were more frequent than single infections (Table 3). IHC-proven cases of $P$. multocida infections showed co-infections with B. bronchiseptica (11), M. felis (6), $M$. gateae (9), and FHV-1 (3). Single infections with $P$. multocida occurred in six cases. Lungs positive for $B$. bronchiseptica had frequent co-infections with other bacteria, such as $P$. multocida (11), M. felis (5), M. gateae (5), but there were also single FHV-1 co-infections (2). There were only four single infections with $B$. bronchiseptica. All but one

Table 3. Co-infections with selected pathogens in feline pneumonias, as revealed by immunohistochemistry and, in case of $M y c o p l a s m a$, supported by PCR

\begin{tabular}{|c|c|c|c|c|c|c|}
\hline & P. multocida & B. bronchiseptica & M. felis & M. gateae & FHV-1 & T. gondit \\
\hline P. multocida & & 11 & 6 & 9 & 3 & 0 \\
\hline B. bronchiseptica & 11 & & 5 & 5 & 2 & 0 \\
\hline M. felis & 6 & 5 & & 3 & 3 & 0 \\
\hline M. gateae & 9 & 5 & 3 & & 1 & 0 \\
\hline FHV-1 & 3 & 2 & 3 & 1 & & 1 \\
\hline T. gondii & 0 & 0 & 0 & 0 & 1 & \\
\hline
\end{tabular}


Mycoplasma infections showed bacterial co-infections, either with P. multocida (M. felis: 1; M. gateae: 2), B. bronchiseptica (M. felis: 2; M. gateae: 0) or both (M. felis: 2; M. gateae: 4). The three double infections with $M$. felis and $M$. gateae were either co-infected with $P$. multocida (2) or with both P. multocida and B. bronchiseptica (1). Three $M$. felis cases had co-infections with FHV-1. One of them was additionally infected with $M$. gateae. The single case with T. gondii infection was also positive for FHV-1. Lungs positive for $\mathrm{FHV}-1$ were single infections in seven cases. Six cases had co-infections with at least one additional pathogen, P. multocida (3), B. bronchiseptica (1), M. felis (3), and T. gondii (1) and one case was simultaneously co-infected with $P$. multocida, B. bronchiseptica, M. felis and M. gateae.

\section{DISCUSSION}

In this retrospective study of archived lung samples showing pneumonic lesions in cats, in $59.4 \%$ of the cases at least one of the featured pathogens was found. The majority of these cases $(61.0 \%)$ were affected with mixed infections with two or more agents. Because the selection of pathogens investigated was arbitrary and did not cover all relevant agents of feline pneumonias, the numbers of agents present per case and the total percentage of mixed infections must be estimated to be much higher. In a comparable study on canine pneumonias, there was also a considerable proportion of mixed infections (Wöhrer et al., 2016).

Single infections were most frequently seen with FHV-1. In seven cats a single infection with FHV-1 was present, and secondary infections with bacterial agents occurred in less than half of the investigated cases. Lung lesions associated with FHV-1 pneumonia are characterised by extensive necrosis of respiratory epithelium, including the bronchiolar and bronchial lining (Leeming et al., 2006; Chvala-Mannsberger et al., 2009; Monne Rodriguez et al., 2017), a lesion which was also consistently present in our samples. In several cases the primary lesions were accompanied by suppurative inflammation that has to be considered the product of bacterial superinfections. FHV-1 pneumonia is regarded as the primary lesion, which then facilitates secondary infections of the lungs (Monne Rodriguez et al., 2018).

Clinical and experimental studies have shown B. bronchiseptica to be a primary respiratory pathogen in cats (Jacobs et al., 1993; Coutts et al., 1996; Hoskins et al., 1998). This pathogen has been found in almost $30 \%$ of all pneumonic cats covered by this study. The presence of mostly large colonies of these bacteria within lung lesions underlines their putative role as a primary causative agent. This notion, however, is frequently confounded by the rather high number of co-infections with other bacteria, as there were only four cases (20\%) in which no other featured pathogen was found. This morphology-based study does not allow determining which of the detected pathogens was the primary infective agent and which were secondary ones. However, in accordance with previous studies we assume that $B$. bronchiseptica may have been the primary agent.

Pasteurella multocida was the most frequent pathogen in this study. Almost $35 \%$ of the examined lungs were positive. About a fourth of the cases (24\%) were single infections. This observation, together with the abundant multiplication of the agent within lesion sites, suggests a role of $P$. multocida as the primary pathogen of pneumonias in cats. Frequently there were co-infections with B. bronchiseptica. In these cases, as stated above, it is not clear which of the two pathogens has to be considered the primary agent. Generally, P. multocida has been shown to be part of the normal oropharyngeal microbiota in different animals but can act as pathogen in numerous species, including humans and dogs (Wöhrer et al., 2016). It often causes serious diseases, such as septicaemia (Kimura et al., 2004). This observation is corroborated by our finding that five out of six cases with signs of septicaemia in our investigated samples were positive for $P$. multocida.

An intriguing finding was the high number of $\mathrm{Myco}$ plasma-positive cases found by IHC. This method suggested a high proportion of double infections with both included Mycoplasma species. Molecular data, however, showed that double infections were only exceptionally present and most cases that reacted positive with both the $M$. felis and the $M$. gateae antibodies were in fact single infections with one of these Mycoplasma species. The used polyclonal antibodies showed frequent cross-reactions, which has been observed already earlier (Wöhrer et al., 2016). This finding also makes clear that immunohistochemistry-based data achieved with antibodies against bacteria within the same genus have to be viewed with caution and should be confirmed using other methods. Unfortunately, PCR amplification failed in several paraffin-wax-embedded samples and thus no information on the identity of some of the immunohistochemically demonstrated mycoplasmas is available. While M. felis is increasingly considered an agent capable of colonising the lower respiratory tract (Lee-Fowler, 2014), this ability of $M$. gateae and other feline Mycoplasma species is less clear. Previous studies showed that Mycoplasma sp. are frequently present in samples from the respiratory tract of both diseased and healthy cats (Holst et al., 2010; Reed et al., 2012; Gourkow et al., 2013; Le Boedec, 2017). While these studies usually used swab samples from the upper respiratory tract or - less frequently - bronchoalveolar lavage samples from the lower respiratory tract, for which contamination with microbes from the upper respiratory tract cannot be categorically prevented (Schulz et al., 2014), the present study is the first one morphologically showing these bacteria within tissue lesions. Although it is generally difficult to claim a pathogenic role for agents that are considered part of the physiological microbiota of the upper respiratory tract, some authors - at least under certain circumstances - attributed them a causative role in certain cases of feline pneumonia (Chandler and Lappin, 2002; Trow et al., 2008; Bongrand et al., 2012; Reed et al., 2012). This assumption was supported by the lack of Mycoplasma in the lower airways of healthy cats (Lee-Fowler, 2014) and 
the isolation of large numbers of Mycoplasma in pure growth without evidence for the involvement of other microbes in pneumonic cats (Foster et al., 2006). Pneumonias with $M$. felis (but not with $M$. gateae) co-infections were predominantly found in cats originating from animal shelters, an observation which emphasised the higher infection pressure of this agent in this particular environment. This observation is in line with a recent meta-analysis indicating a higher percentage of asymptomatic carrier animals in shelters that may give rise to more M. felis-complicated pneumonias in shelter cats (Le Boedec, 2017). Concerning the pathogenicity of Mycoplasma for the feline respiratory tract, our findings lead to two conclusions: $M$. felis can multiply to very high numbers in the lung tissue, but this event is only observed when other pathogens, e.g. B. bronchiseptica, $P$. multocida or both have initiated substantial lung lesions. As M. felis has never appeared as a single infectious agent, we assume that it may only aggravate pneumonias that have been initiated by other pathogens. Molecularly proven cases of $M$. gateae infections were characterised by focal bacterial colonies of minor extension. In these 'real' M. gateae infections, this agent also colonised the lung tissue damaged by other pathogens but, in contrast to M. felis, it did not multiply very efficiently. Thus, $M$. gateae does not seem to contribute to additional lung damage and has to be considered as a mere rather benign bystander.

A ten-week-old FHV-1-positive kitten had generalised toxoplasmosis, which also affected the lung. This finding is in line with previous descriptions of feline toxoplasmosis (Dubey and Carpenter, 1993). Compared with viral or bacterial pathogens, protozoa seem to be rare causative agents of feline pneumonias.

Not surprisingly, no cases of CDV or FCoV were associated with feline pneumonias. So far, all attempts of screening for a potential pathogenicity of CDV in cats have proved negative (Bart et al., 2000), which is also confirmed by the present survey. Because the presence of classical effusive or granulomatous feline infectious peritonitis with thoracic manifestation had been an exclusion criterion during case selection, only different types of pneumonias with no macroscopic or histologic suspicion of FIP were investigated. The negative outcome showed that $\mathrm{FCoV}$ is not involved in respiratory diseases in cats. A long time ago the term 'feline pneumonitis' has been created in context with chlamydial infections in cats (Baker, 1942, 1944). However, the term is misleading because there is no evidence that chlamydiae have ever been involved in natural cases of lower respiratory tract disease (Bart et al., 2000). This fact is also corroborated by the present study that also showed no cases of chlamydial infections in the investigated lung samples.

The initial intention also to screen for feline calicivirus antigen in this study had to be discarded after the available antibodies showed unspecific reaction in negative control samples. We are convinced, however, that this virus is present in a proportion of the samples investigated.

The present study did not reveal any noteworthy sex preference, i.e. the positive cases for all investigated pathogens were evenly distributed among both sexes. This observation is in some contrast to previous studies in which males were 2.4 times more likely to have lower respiratory tract infections than females (Foster et al., 2004a). Interestingly, in a recent retrospective study on fatal FHV-1-associated pneumonia, all the cases were male (ChvalaMannsberger et al., 2009).

The study also did not show any particular strong correlation between the type of the infectious agent and age. Although the low case numbers within the age groups did not allow statistic testing, there is a tendency towards young age in FHV-1 and P. multocida infections, while infections with $M$. felis were more frequent in the adult age group. This is an unexplained contrast to the findings of previous studies (Chvala-Mannsberger et al., 2009; Monne Rodriguez et al., 2018).

Taken together, the present study showed that FHV-1 is a relevant causative agent of feline pneumonias and that the bacterial agents $B$. bronchiseptica and P. multocida are frequently involved, with approximately half of the cases presenting as co-infections with both agents. Mycoplasma spp. do not seem to act as primary pathogens, and due to its more efficient multiplication in damaged lung tissue $M$. felis is considered to contribute more to increasing the severity of lung lesions in co-infected lungs than M. gateae.

\section{ACKNOWLEDGEMENTS}

The authors kindly thank Ingrid Friedl and Madeleine Lunardi for their excellent technical assistance and Klaus Bittermann for his help with editing the digital images. Joachim Spergser is gratefully acknowledged for the kind gift of antibodies to P. multocida, and for cultures of and antibodies to M. felis and M. gateae. We also thank Karen Register for providing antibodies to B. bronchiseptica.

\section{REFERENCES}

Ames, T. R., Markham, R. J. F., Opuda-Asibo, J., Leininger, J. R. and Maheswaran, S. K. (1985): Pulmonary response to intratracheal challenge with Pasteurella multocida. Can. J. Comp. Med. 49, 395-400.

Appel, M., Sheffy, B. E., Percy, D. H. and Gaskin J. M. (1974): Canine distemper virus in domestic cats and pigs. Am. J. Vet. Res. 35, 803-806.

Baker, J. A. (1942): A virus obtained from a pneumonia of cats and its possible relation to the cause of atypical pneumonia in man. Science 20, 475-476.

Baker, J. A. (1944): A virus causing pneumonia in cats and producing elementary bodies. J. Exp. Med. 79, 159-172.

Bannasch, M. J. and Foley, J. E. (2005): Epidemiologic evaluation of multiple respiratory pathogens in cats in animal shelters. J. Fel. Med. Surg. 7, 109-119.

Bart, M., Guscetti, F., Zurbriggen, A., Pospischil, A. and Schiller I. (2000): Feline infectious pneumonia: a short literature review and a retrospective immunohistological study on the 
involvement of Chlamydia spp. and distemper virus. Vet. J. 159, 220-230.

Bongrand, Y., Biais, M. C. and Alexander, K. (2012): Atypical pneumonia associated with a Mycoplasma isolate in a kitten. Can. Vet. J. 53, 1109-1113.

Campbell, L. H., Snyder, S. B., Reed, C. and Fox, J. G. (1973): Mycoplasma felis-associated conjunctivitis in cats. J. Am. Vet. Med. Assoc. 163, 991-995.

Chandler, J. C. and Lappin, M. R. (2002): Mycoplasmal respiratory infections in small animals: 17 cases (1988-1999). J. Am. Anim. Hosp. Assoc. 38, 111-119.

Chvala-Mannsberger, S., Bago, Z. and Weissenböck, H. (2009): Occurrence, morphological characterization and antigen localization of felid herpesvirus-induced pneumonia in cats: a retrospective study (2000-2006). J. Comp. Pathol. 141, 163169.

Coutts, A. J., Dawson, S., Binns, S., Hart, C. A. and Gaskell, C. J. (1996): Studies on natural transmission of Bordetella bronchiseptica in cats. Vet. Microbiol. 48, 19-27.

Dubey, J. P. and Carpenter, J. L. (1993): Histologically confirmed clinical toxoplasmosis in cats: 100 cases (1952-1990). J. Am. Vet. Med. Assoc. 203, 1556-1566.

Foley, J. E., Rand, C., Bannasch, M. J., Norris, C. R. and Milan, J. (2002): Molecular epidemiology of feline bordetellosis in two animal shelters in California, USA. Prev. Vet. Med. 54, 141156.

Foster, S. F. and Martin, P. (2011): Lower respiratory tract infections in cats: reaching beyond empirical therapy. J. Fel. Med. Surg. 13, 313-332.

Foster, S. F., Barrs, V. R., Martin, P. and Malik R. (2006): Pneumonia associated with Mycoplasma spp. in three cats. Aust. Vet. J. 76, 460-464.

Foster, S. F., Martin, P., Allan, G. S., Barrs, V. R. and Malik, R. (2004a): Lower respiratory tract infections in cats: 21 cases (1995-2000). J. Fel. Med. Surg. 6, 167-180.

Foster, S. F., Martin, P., Braddock, J. A. and Malik, R. (2004b): A retrospective analysis of feline bronchoalveolar lavage cytology and microbiology (1995-2000). J. Fel. Med. Surg. 6, 189-198.

Gaskell, R. M. and Dawson, S. (1998): Feline respiratory disease. In: Greene, C. E. (ed.) Infectious Diseases of the Dog and Cat. 2nd ed. W. B. Saunders, Philadelphia. pp. 97-106.

Gaskell, R. M. and Povey, R. (1973): Re-excretion of feline viral rhinotracheitis virus following corticosteroid treatment. Vet. Rec. 93, 204-205.

Gaskell, R. M. and Povey, R. C. (1977): Experimental induction of feline viral rhinotracheitis virus re-excretion in FVR-recovered cats. Vet. Rec. 100, 128-133.

Gaskell, R., Dawson, S., Radford, A. and Thiry, E. (2007): Feline herpesvirus. Vet. Res. 38, 337-354.

Gourkow, N., Lawson, J. H., Hamon, S. C. and Phillips, C. J. C. (2013): Descriptive epidemiology of upper respiratory disease and associated risk factors in cats in an animal shelter in coastal western Canada. Can. Vet. J. 54, 132-138.

Haesebrouck, F., Devriese, L. A., van Rijssen, B. and Cox, E. (1991): Incidence and significance of isolation of Mycoplasma felis from conjunctival swabs of cats. Vet. Microbiol. 26, 95-101.

Holst, B. S., Hanas, S., Berndtsson, L. T., Hansson, I., Soderlund, R., Aspan, A., Sjodahl-Essen, T., Bolske, G. and Greko, C. (2010):
Infectious causes for feline upper respiratory tract disease - a case-control study. J. Feline Med. Surg. 12, 783-789.

Hoover, E. A., Kahn, D. E. and Langloss, J. M. (1978): Experimentally induced feline chlamydial infection (feline pneumonitis). Am. J. Vet. Res. 39, 541-547.

Hoskins, J. D., Williams, J., Roy, A. F., Peters, J. C. and McDonough, P. (1998): Isolation and characterization of Bordetella bronchiseptica from cats in southern Louisiana. Vet. Immunol. Immunopathol. 65, 173-176.

Jacobs, A. A. C., Chalmers, W. S. K., Pasman, J., Van Vugt, F. and Cuenen, L. H. (1993): Feline bordetellosis: challenge and vaccine studies. Vet. Rec. 133, 260-263.

Kimura, R., Hayashi, Y., Takeuchi, T., Shimizu, M., Iwata, M., Tanahashi, J. and Ito, M. (2004): Pasteurella multocida septicemia caused by close contact with a domestic cat: case report and literature review. J. Infect. Chemother. 10, 250-252.

Kipar, A., Meli, M. L., Failing, K., Euler, T., Gomes-Keller, M. A., Schwartz, D., Lutz, H. and Reinacher, M. (2006): Natural feline coronavirus infection: differences in cytokine patterns in association with the outcome of infection. Vet. Immunol. Immunopathol. 112, 141-155.

Le Boedec, K. (2017): A systemic review and meta-analysis of the association between Mycoplasma spp. and upper and lower respiratory tract disease in cats. J. Am. Vet. Med. Assoc. 250, 397-407.

Lee-Fowler, T. (2014): Feline respiratory disease: what is the role of Mycoplasma species? J. Fel. Med. Surg. 16, 563-571.

Leeming, G., Meli, M. L., Cripps, P., Vaughann-Thomas, A., Lutz, H., Gaskell R. and Kipar, A. (2006): Tracheal organ cultures as a useful tool to study felid herpesvirus 1 infection in respiratory epithelium. J. Virol. Methods 138, 191-195.

Liehmann, L., Degasperi, B., Spergser, J. and Niebauer, G. W. (2006): Mycoplasma felis arthritis in two cats. J. Small Anim. Pract. 47, 476-479.

Monne Rodriguez, J., Köhler, K. and Kipar, A. (2018): Calicivirus co-infections in herpesvirus pneumonia in kittens. Vet. J. 236, $1-3$.

Monne Rodriguez, J., Leeming, G., Köhler, K. and Kipar, A. (2017): Feline herpesvirus pneumonia: investigations into the pathogenesis. Vet. Pathol. 54, 922-932.

Pedersen, N. C. (1987): Virologic and immunologic aspects of feline infectious peritonitis virus infection. Adv. Exp. Med. Biol. 218, 529-550.

Pedersen, N. C., Boyle, J. F., Floyd, K., Fudge, A. and Barker, J. (1981): An enteric coronavirus infection of cats and its relationship to feline infectious peritonitis. Am. J. Vet. Res. 42, 368-377.

Reed, N., Simpson, K., Ayling, R., Nicholas, R. and Gunn-Moore D. (2012): Mycoplasma species in cats with lower airway disease: improved detection and species identification using a polymerase chain reaction assay. J. Fel. Med. Surg. 14, 833840.

Rosendal, S. (1982): Canine mycoplasmas: their ecologic niche and role in disease. J. Am. Vet. Med. Assoc. 180, 1212-1214.

Schulz, B. S., Richter, P., Weber. K., Mueller, R. S., Wess, G., Zenker, I. and Hartmann, K. (2014): Detection of feline Mycoplasma species in cats with feline asthma and chronic bronchitis. J. Fel. Med. Surg. 16, 943-949. 
Trow, A. V., Rozanski, E. and Tidwell, A. S. (2008): Case report: primary mycoplasma pneumonia associated with reversible respiratory failure in a cat. J. Fel. Med. Surg. 10, 398-402.

Willoughby, K., Dawson, S., Jones, M. R. C., Symons, M., Daykin, J., Payne-Johnson, C., Gaskell, R. M., Banett, M. and Gaskell, C. J. (1991): Isolation of B. bronchiseptica from kittens with pneumonia in a breeding cattery. Vet. Rec. 129, 407-408.
Wöhrer, D., Spergser, J., Bagrinovschi, G., Möstl, K. and Weissenböck, H. (2016): Age-related presence of selected viral and bacterial pathogens in paraffin-embedded lung samples of dogs with pneumonia. Acta Vet. Hung. 64, 103-115.

Zeugswetter, F., Hittmair, K. M., Guija de Arespacochaga, A., Shibly, S. and Spergser, J. (2006): Erosive polyarthritis associated with Mycoplasma gateae in a cat. J. Fel. Med. Surg. 9, 226-231. 